Vol. 21 (2017), pp. 109-127

ISSNe: 2530-6324 || ISSN: 1138-039X

DOI: https://doi.org/10.17979/afdudc.2017.21.0.3273

\title{
PERSPECTIVAS ACTUALES DEL DERECHO. BIO POLITICA Y BIO-JURIDICIDAD. INCIDENCIA EN EL ESTUDIO Y APLICACIÓN DEL DERECHO ADMINISTRATIVO
}

\author{
FERNANDO R. GARCÍA PULLÉS \\ Profesor titular de Derecho Administrativo \\ de la Facultad de Derecho de la Universidad de Buenos Aires \\ Presidente de la Asociación Argentina de Derecho Administrativo.
}

Resumen: El hombre se ubica en el centro de la tensión entre el poder y el derecho. La historia exhibe que la vinculación entre estos dos últimos términos carece de sustancia cuando se la plantea en términos binarios, despojada del presupuesto condicionante de la dignidad humana. Es necesario advertir que la realidad actual exige una respuesta que supere las técnicas de la biopolítica y se apoye en el valor de la dignidad humana como concepto central de toda funcionalidad del derecho. Esta nueva perspectiva encuentra particular significación en el diseño de las políticas, las regulaciones y el examen de las instituciones de derecho administrativo. Los ejemplos de la evolución en Argentina.

Palabras clave: Administración y dignidad humana; Poder y Derecho; Persona y ser humano; Derecho, realidad y dignidad; Bio-política y bio-juridicidad.

\begin{abstract}
Since ancient times Human dignity has been the nuclear issue in the tense relationship between Goverment and Law. History shows that a binarian point of view, when stripped from the qualification given by human dignity over those elements in conflict, is flawed. Present day society requires policies which dispenses with the techniques of "Biopolitics" in favor of a new concept, "the bio-juridicity" as a starting point to interpret the Law. This criterion is central to the construction of administrative policies, regulations and institutions. Argentina Case law examples reflect this development.
\end{abstract}

Keywords: Administration and human dignity; Power and Law; Fairness; Personae and human being; Law, reality and dignity; Bio-politics and Bio-juridicity 
SUMARIO: I. INTRODUCCIÓN. II. PODER, ORDENAMIENTO JURIDICO Y SER HUMANO. 2.1. Los componentes de una relación tripartita. 2.2. Algunos antecedentes. Control del poder desde factores externos a la dignidad inherente al ser humano. 2.3. El constitucionalismo. Proclamada humanización del poder y el derecho que termina en la subordinación a la mera legalidad. 2.4. La respuesta del poder. La bio-política. 2.5. Biopolítica y derechos humanos. III.- UNA RESPUESTA A LA BIO-POLITICA, LA BIO-JURIDICIDAD. IV.- LAS CATEGORIAS INTERPRETATIVAS DE LA BIOJURIDICIDAD. V.- LA BIOJURIDICIDAD Y EL DERECHO ADMINISTRATIVO. VI. UNA INVITACION PENDIENTE

\section{INTRODUCCIÓN.}

En el prólogo de "Las personas y las cosas", sostiene Roberto Espósito que "ningún cambio real en nuestras formas políticas actuales es imaginable sin una modificación igualmente profunda de nuestras categorías interpretativas". Invito a considerar una extensión de esta proposición en dos sentidos:

(i) Para el territorio del derecho, podríamos parafrasear a Espósito y decir que ninguna modificación real de nuestras instituciones jurídicas actuales puede darse sino a partir de valorar los cambios de la realidad a la que se destinan aquellas y de la correlativa modificación de las categorías con las que dicha realidad debe ser interpretada.

(ii) Para los dominios de la seguridad jurídica, tantas veces anhelada, también podría proponerse que ningún cambio de la ciencia jurídica podrá perdurar, en su validez intrínseca y aceptación social, si no se asienta sobre la premisa de una constante búsqueda de su adaptación a la realidad sobre la que ha de aplicarse y de las alteraciones en las categorías interpretativas que iluminan esa realidad.

Es que, como no me canso de repetir, cada trabajo académico es una oportunidad para la reflexión, para hacer y recibir llamados de atención que convoquen nuestras voces más profundas. Quienes desandamos los caminos de esta Nación bendita y vemos los signos de los tiempos que nos rodean, en el campo del derecho administrativo, nos vemos obligados a formularnos algunas preguntas trascendentes, a saber: ¿Es la política y, más estrictamente, la aplicación de las políticas públicas que aquí hacemos, una contribución a la consolidación de los derechos sociales? ¿Existe una alternativa efectiva de control social sobre las políticas públicas destinadas a la realización de los derechos sociales? ¿Es el derecho público, y más estrictamente la aplicación del derecho público que aquí hacemos, una herramienta con la que se procura la realización humana de las personas en general, y de las más necesitadas de protección en particular?

Hace unos meses, en el marco de una Jornada realizada en la Universidad de Buenos Aires, recordé unos párrafos del documento del Papa Francisco llamado el Gozo en el Evangelio, con palabras que trascienden claramente a cualquier credo y que me parece oportuno recodar aquí: 
Señaló el Pontífice en dicho documento:

"218. La paz social no puede entenderse como la mera ausencia de violencia lograda por la imposición de un sector sobre los otros... o la excusa para justificar una organización social que silencie o tranquilice a los más pobres, de manera que aquellos que gozan de los mayores beneficios puedan sostener su estilo de vida sin sobresaltos mientras los demás sobreviven como pueden".

"Las reivindicaciones sociales, que tienen que ver con la distribución del ingreso, la inclusión social de los pobres y los derechos humanos, no pueden ser sofocadas con el pretexto de construir un consenso de escritorio o una efímera paz para una minoría feliz. La dignidad de la persona humana y el bien común están por encima de la tranquilidad de algunos que no quieren renunciar a sus privilegios. Cuando estos valores se ven afectados, es necesaria una voz profética".

"En cada nación, los habitantes desarrollan la dimensión social de sus vidas configurándose como ciudadanos responsables en el seno de un pueblo, no como masa arrastrada por las fuerzas dominantes. ... Ser ciudadano fiel es una virtud y la participación en la vida política es una obligación moral». Pero convertirse en pueblo es todavía más, y requiere un proceso constante en el cual cada nueva generación se ve involucrada. Es un trabajo lento y arduo que exige querer integrarse y aprender a hacerlo hasta desarrollar una cultura del encuentro en una pluriforme armonía".

“221. Para avanzar en esta construcción hay cuatro principios ... que orientan específicamente el desarrollo de la convivencia social y la construcción de un pueblo donde las diferencias se armonicen en un proyecto común: ... a) El tiempo es superior al espacio. b) La unidad prevalece sobre el conflicto. c) La realidad es más importante que la idea. d) El todo es más que la parte, y también es más que la mera suma de ellas. Entonces, no hay que obsesionarse demasiado por cuestiones limitadas y particulares. Siempre hay que ampliar la mirada para reconocer un bien mayor que nos beneficiará a todos. Pero hay que hacerlo sin evadirse, sin desarraigos"

Sin perder el valor axiológico del derecho, entiendo importante instigar a hacer una reflexión, desde la perspectiva que brindan unas pocas consideraciones metodológicas, porque el derecho sigue siendo sólo y nada menos que una herramienta para construir una realidad más justa para el hombre y no una realidad que pueda construirse con el hombre como uno más de sus recursos. 


\section{PODER, ORDENAMIENTO JURIDICO Y SER HUMANO.}

\subsection{Los componentes de una relación tripartita.}

La relación de conflicto entre poder y derecho es un dato esencial de la realidad humana y sus raíces pueden bucearse hasta los más antiguos hitos de la historia. No dejo de considerar que Balbín ${ }^{1}$, entre nosotros, ha indicado que esta relación se teje entre derecho (de la sociedad) y derecho (de los ciudadanos individuales). Pero en una u otra consideración, no es dudoso que ese conflicto se presenta tan añejo como el hombre.

La evolución de la cultura ha examinado esta relación desde perspectivas singularmente diversas: políticas, económicas, religiosas, morales, filosóficas y, sobre todo, jurídicas.

La reducción binaria de este conflicto a una ecuación poder - ordenamiento implica soslayar un tercer término en la relación autoridad-juridicidad, que es justamente el centro de ambas tópicas: el ser humano. Considerar sólo aquella aparente bipolaridad nos conduce siempre a la lograda alegoría de Alejandro Nieto: "En el principio había una potestad y un ordenamiento". La introducción del ser humano en dicha ecuación exige un análisis trinitario y más profundo que propone que "en el principio había seres humanos cuya interferencia intersubjetiva justificaron el nacimiento de una potestad y un ordenamiento" .

Es que el examen de la vinculación del poder al concepto abstracto de derecho, enunciado sin teleología, nos conduce a una situación casi quimérica, pues es claramente comprobable que el poder siempre ha pretendido -y la mayoría de las veces logrado- monopolizar la creación jurídica, sin admitir su sujeción a factores exógenos, o utilizando los supuestos valores de control para profundizar el sometimiento de los ciudadanos a las prerrogativas del poderoso.

En una prueba de la frustración que nos presenta el conflicto, concebido desde estas únicas dos variables, Gastón Jéze prologó la obra "El Estado" de Woodrow Wilson afirmando que "...después de un cuarto de siglo consagrado al estudio del derecho y de la política, he llegado a esta convicción profunda: que todo estudio o ciencia social no tiene más razón de ser o valor que el de formular una regla de conducta que imponga su respeto a los gobernantes", describe toda su debilidad.

Es que la idea de un poder limitado exclusivamente desde las normas jurídicas, sin considerar al ser humano como un condicionante que las trasciende, vaciaría de contenido la vinculación de aquel al derecho, haciéndola meramente formal, formalidad que justamente ha utilizado el poder para anonadar esta perspectiva de sujeción.

\subsection{Algunos antecedentes. Control del poder desde factores externos a la dignidad inherente al ser humano.}

\footnotetext{
${ }^{1}$ Balbín, Carlos - Curso de Derecho Administrativo, Ed. La Ley, Bs.As. 2007, Tomo I, pág. 95, punto IV.

2 .- Es evidente la reminiscencia de la teoría egológica que la postulación encierra.

3.- Woodrow Wilson - El Estado - con prólogo de León Duguit - Ed. V.Giard \& Briere - París 1902.
} 
Si entendemos esta relación como tripartita: poder-derecho-ser humano, un somero examen de antecedentes nos permitiría advertir qué elemento se constituyó, en cada tiempo, en eje de la regulación del poder.

En las leyes 33 y 34 del Código de Hammurabi se sancionan con la muerte dos casos de abuso de poder, en un contexto en el que los derechos se atribuían a los soldados o a los propietarios de la tierra, y no a las mujeres y los esclavos, cuya condición de sujetos del derecho era negada. En el prólogo de ese código, Hammurabi indica que los Dioses le encomendaron que mostrase la Equidad al País, para destruir al malvado y al inicuo, para que el prepotente no oprima al débil, para iluminar la tierra y promover el bienestar de la gente. Un poder de crear el derecho derivado de una instrucción divina, en la que el ser humano no juega otro rol que no fuera el de destinatario de las normas. Algo similar podría decirse de las tablas de la ley mosaica.

La tradición griega, en especial sus filósofos, parecieron sublimar el concepto de persona. Sin embargo, limitaron la atribución de esta calidad a los ciudadanos y enfrentaron al poder desde perspectivas no causadas por el respeto al ser humano en cuanto tal, tanto por la disociación entre la noción de persona y la de "ser humano", como porque relativizaron el valor de su dignidad inherente como condicionante de la procura del interés público, al punto de entronizar a éste por encima de la dignidad del hombre.

En este sentido, en la consideración de la mujer y la eutanasia espartana, la pureza racial del pueblo se arroga el derecho de dirigir las relaciones conyugales y el de hacer morir o dejar vivir a los discapacitados ${ }^{4}$, mientras que, en la "Politica" de Aristóteles se sostiene que: "...las posesiones son un instrumento para la vida y la propiedad es una multitud de instrumentos; también el esclavo es una posesión animada, y todo subordinado es como un instrumento previo a los otros instrumentos" y, más adelante, “...el que, siendo hombre, no se pertenece por naturaleza a sí mismo, sino a otro, ese es por naturaleza esclavo. Y es hombre de otro el que, siendo hombre es una posesión"5. la muerte de Sócrates, la institucionalidad de la polis prevalece y concreta un hacer morir fundado en el desvío del poder y la injusticia.

El primitivo derecho romano estuvo basado en el corpus iuris civilis, que se transformó desde entonces en el derecho común. Pero la pax romana fue un eclipse que exhibía hacia adentro un derecho civil de igualdad para los "pater familias", mientras justificaba la apropiación de las cosas y de otros hombres o de las mujeres como botín de conquista. El poder de las armas y la violencia imponía un derecho surgido de ellas para hacer morir.

En la patrística católica, la Paz Agustiniana se define como la tranquilidad de las cosas en el orden, aunque es claro que ese orden surge del mandato de la Divina Providencia. La validez del derecho se sujeta a ese orden divino, que determina el hacer morir o dejar vivir, pues de qué otro modo podrían justificarse las matanzas de arrianos y judíos de Recaredo luego de su conversión al catolicismo en España.

También es clara la sujeción del poder y del derecho a la ley eterna, en la explicación de Santo Tomás de Aquino sobre la formación del derecho natural, como participación

\footnotetext{
${ }_{5}^{4}$ Plutarco - Vidas Paralelas - Vida de Licurgo, Nros. 15 y 16, entre otros, Ed. Gredos, Madrid.

${ }^{5}$ Aritstóteles - La política - Ed. Gredos, Madrid 1994, pags. 54 y 56.
} 
racional en aquella ley divina inmutable, que constituye la vara de medida para el poder y la juridicidad. También aquí el poder buscó anclar en la ley divina el derecho de hacer morir o dejar vivir, como ocurriera en la Inquisición.

No dejo de advertir que la invocación de Dios, de la Ley Eterna y del Derecho Natural como participación racional del hombre en aquella, supone también la jerarquización del valor de la dignidad de la criatura humana. Sin embargo, en muchos expositores se pierde esta conexión que encarna la verdadera fuente de sujeción al poder, dejándola expresada en la mera relación con la Ley Divina Positiva.

Esa consideración de la relación entre el derecho y el poder desde una perspectiva externa y hasta prescindente del valor intrínseco del ser humano continuó con el racionalismo, el pragmatismo, las categorías gnoseológicas y el imperativo categórico Kantiano, el idealismo Hegeliano y más tarde el materialismo histórico, la dialéctica histórica de Marx, el superhombre de Nietzsche, el personalismo utilitarista de Singer.

De distintas maneras, en todos estos idearios el ser humano -en su integralidad- quedó subordinado a una relación poder-derecho regulada por fuerzas ajenas a su dignidad intrínseca (sujeción a reglas generales codificadas por el racionalismo, la contribución al logro de la razón pura y la moral abstracta, la realización de la conveniencia empírica, la integración a la idea absoluta frente al nihilismo, la promoción de la lucha de clases, el logro de una nueva ataraxia supernatural, la concreción de una supuesta sociedad más justa, su salvación eterna, entre otros).

Quiero advertir especialmente que no pretendo subestimar estas justificaciones ni las finalidades que las animan -he compartido y abrevo de las virtudes del jusnaturalismo y de las enseñanzas católicas- sólo quiero mostrar que muchas veces sus bases han sido cuestionadas por su origen confesional, sus cauce filosófico, económico o cultural y, en definitiva, por cuanto justificaron que el poder, por sí o con invocación de aquellos fines y de las normas que él mismo creaba, se atribuyera la potestad de hacer morir o dejar vivir al hombre.

Estas alternativas, claramente asignables a Dios en una perspectiva trascendente a la política o la jurídica, no reciben parecida justificación en el ámbito del conflicto entre el poder, el ser humano y el derecho, cuando se invoca basada en el racionalismo cartesiano, la voluntad popular, el pragmatismo, la razón pura, la lucha de clases, la norma positiva sancionada con los procedimientos requeridos por el ordenamiento, la idea abstracta sobre qué es una sociedad más justa o el logro de los fines del estado absoluto, entre otros.

\subsection{El constitucionalismo. Proclamada humanización del poder y el derecho que termina en la subordinación a la mera legalidad}

El constitucionalismo pareció destinado a recuperar la centralidad del ser humano en la relación entre poder y derecho. La declaración de Filadelfia de 1776 y la Declaración de los Derechos del Hombre y del Ciudadano de 1789 inducen a pensar que brotaba en la comunidad política esa idea de derechos inherentes a la dignidad del ser humano que no dependían del poder o del derecho. 
Se dice en la declaración de independencia americana que resulta evidente "...que todos los hombres son creados iguales; que son dotados por su Creador de ciertos derechos inalienables; que entre estos están la vida, la libertad y la búsqueda de la felicidad; que para garantizar estos derechos se instituyen entre los hombres los gobiernos, que derivan sus poderes legítimos del consentimiento de los gobernados..."6

El principal documento de la Revolución Francesa lleva una Declaración solemne sobre “...los derechos naturales, inalienables y sagrados del Hombre, para que esta declaración, constantemente presente para todos los Miembros del cuerpo social, les recuerde sin cesar sus derechos y sus deberes; para que los actos del poder legislativo y del poder ejecutivo, al poder cotejarse en todo momento con la finalidad de cualquier institución política, sean más respetados y para que las reclamaciones de los ciudadanos, fundadas desde ahora en principios simples e indiscutibles, redunden siempre en beneficio del mantenimiento de la Constitución y de la felicidad de todos..."7.

Sin embargo, aquellas declaraciones iniciales fueron atrapadas por el racionalismo y su vocación de establecer normas abstractas generales. Así, al bucear en la letra de estos mismos documentos se advierte una prevalencia de la voluntad general sobre esos derechos inmanentes, que justificó las normas constitucionales que atribuyeron a la ley, sublimándose su condición de instrumento de la voluntad popular, la posibilidad de ensanchar o anonadar aquellos derechos supuestamente inalienables.

Tómese como ejemplo la segunda parte del artículo 19 de la Constitución Argentina, según la cual "Ningún habitante puede ser obligado a hacer lo que la ley no manda ni privado de lo que ella no prohíbe" para advertir que, a contramano del mismo espíritu de aquellas declaraciones iniciales del constitucionalismo, siguió pensándose en un derecho derivado del ordenamiento jurídico y no preexistente a él.

Y si esta mención pareciera equívoca, véase que el artículo 33 de la Ley Suprema, cuando alude a que la enumeración anterior no implica negación de otros derechos, se refiere explícitamente a que estos otros "...nacen del principio de la soberanía del pueblo y de la forma republicana de gobierno...”.

Mi buen amigo Claudio Viale, que ha sufrido respecto de este pequeño trabajo el "despótico derecho del autor de una obra inédita sobre el tiempo de los demás a los que obliga a su lectura", me ha advertido que esta denuncia ya fue hecha en su momento por Jacques Maritain, con una autoridad y claridad insuperables, señalando con agudeza la diversidad entre los acercamientos en las afirmaciones prácticas y los alejamientos en el plano de las interpretaciones y justificaciones racionales, especulativo y teórico? ${ }^{9}$

Por eso, a pesar de aquella aparente mención redentora de los documentos cardinales, lo cierto es que la relación entre derechos inherentes al ser humano y ordenamiento no concretó la preexistencia de aquellos a la ley, y mucho menos su preexistencia a la

\footnotetext{
${ }^{6}$ Ver: https://www.archives.gov/espanol/la-declaracion-de-independencia.html

${ }^{7}$ Ver: http://www.conseil-constitutionnel.fr/conseil-constitutionnel/root/bank_mm/espagnol/es_ddhc.pdf

${ }^{8}$ En la sutil versión de Bioy Casares.

${ }^{9}$ Maritain, Jacques - El hombre y el Estado. Capítulo IV, Los derechos del hombre y sus fundamentos, que puede verse también en www.jacquesmaritain.com/pdf/09
} 
misma norma constitucional fundante del Estado y legitimante del ejercicio del poder soberano.

Así, la declamación originaria sobre el carácter preexistente de la dignidad del hombre devino en una relación que quedó situada en aquella ecuación binaria de la que hablamos al principio: poder-derecho que es, en realidad, poder-poder.

\subsection{La respuesta del poder. La bio-política}

Pero además, poco tiempo bastó para que la revolución industrial y las fuerzas económicas del siglo XIX destruyeran aquel postulado idílico, ya tergiversado en la concreción normativa, para preservar el poder de los gobiernos.

Como expuso descarnadamente Michael Foucault uno de los fenómenos fundamentales de este siglo XIX, que se prolongó hacia el XX es aquel mediante el cual el poder se hizo cargo de la vida humana como un recurso, generándose la "biopolítica""

Se trató de una toma de poder sobre el hombre en tanto que ser viviente, es decir de una especie de apoderamiento de lo biológico ${ }^{11}$. El poder tomó conciencia de que su permanencia dependía no tanto de la muerte de los seres humanos, sino de su supervivencia en el sometimiento.

En ese modo de relación entre poder y derecho, en las palabras de Foucault "...el poder es cada vez. menos el derecho de hacer morir y cada vez más el derecho de intervenir para hacer vivir, que faculta al poder a intervenir sobre la manera de vivir, de intervenir para mejorar la vida, para controlar sus accidentes, los riesgos, las deficiencias, una tecnología de regulación...", pero a la vez, ese mismo poder se presenta como un paralelo derecho a disciplinar, que tiene como fin "...convertir al sujeto en un instrumento dócil y útil en el nuevo orden burgués, ...que pretende controlar (y eventualmente modificar), las probabilidades y en cualquier caso compensar sus efectos ... y que apunta a la seguridad del conjunto en relación con sus peligros internos".

La biopolítica de Foucault se concibe integrada por dos tecnologías de poder -una de regulación y otra disciplinaria-, que, según el grupo político hegemónico y/o la ideología dominante en la sociedad, implantará medidas que abarquen a todos los sujetos humanos o que vayan destinadas hacia unos pocos, que integren o que excluyan, que igualen o discriminen, que repriman y exploten o se decanten por la convivencia, la paz y el bienestar. Que dejen vivir o hagan morir.

En la conjugación de estas dos tecnologías con el reconocimiento de una humanidad parcial, sólo atribuible a una raza, como en Roma sólo lo fuera a los pater familias, o de la que se excluyera a las mujeres y esclavos, las tecnologías de la biopolítica engendraron y explican el nazismo.

\footnotetext{
${ }^{10}$ Ver: Foucault, Michel - El nacimiento de la biopolítica - Ed. Fondo de Cultura Económica, Mexico 2007.

${ }^{11}$ Foucault, Michel - Genealogía del racismo - Paris 1992)
} 


\subsection{Biopolítica y derechos humanos.}

En un estudio reciente, Gorski y Rivera Beiras han sostenido que la bio-política no ha sufrido alteraciones por la admisión de los derechos humanos como categoría, ya que asistimos a la continuidad de sus tecnologías en las medidas de seguridad pública, antiterrorismo, en el tratamiento carcelario y en la discriminación ante los flujos migratorios, denunciando el renacimiento de la teoría de los "campos" en la Europa actual $^{12}$, aludiendo a una continuidad de criterios que sólo quedan disimulados por el disfraz de los derechos humanos.

Esta denuncia se ve potenciada en cada oportunidad en que un atentado terrorista conmueve la doctrina de la "humanidad" europea e impulsa a cada uno de sus integrantes a desoir las bases de su evolución cultural para auspiciar nuevas discriminaciones.

En similar sentido, Hannah Arendt hubo de exponer que los derechos humanos se han convertido en un dispositivo más de las estrategias y herramientas requeridas por el poder para administrar al ser humano, indicando que forman parte del aparato del poder estatal que se despliega para reducir a los individuos a medidas y cifras que manipula una burocracia política, autorizando y cohonestando medidas que protegen la generalidad.

En este sentido, la autora antes citada tuvo oportunidad de sostener que "Allí donde la igualdad se torna un hecho mundano en sí misma, sin ninguna regla por la que pueda ser medida o explicada, allí hay también una probabilidad entre cien de que será considerada como principio viable de una organización política en la que personas de otra manera desiguales tienen derechos iguales; hay noventa y nueve probabilidades de que será confundida con una cualidad innata de cada individuo que es 'normal' si es como todos los demás y 'anormal' si resulta ser diferente. Esta perversión de la igualdad, de un concepto político a un concepto social, es aún mucho más peligrosa cuando una sociedad no deja el más pequeño espacio para los grupos e individuos especiales, porque entonces sus diferencias se tornan aún más conspicuas"13.

\section{III.- UNA RESPUESTA A LA BIO-POLITICA, LA BIO-JURIDICIDAD.}

Sin embargo, tengo para mí que una diversa lectura de la realidad de lo hodierno y del porvenir inmediato es posible y proponible, como elemento que predetermina una nueva visión de aquella relación tripartita ser humano-poder-derecho.

Y ese cambio de enfoque parte de advertir el nacimiento de una hetero-vinculación del poder no ya desde el ordenamiento, que -como se ha dicho- muchas veces es engendrado y modelado por el mismo poder, invocando sustento en la supuesta preservación del interés general, sino desde la humanidad del sujeto que es el destinatario del poder y del ordenamiento, pero cuya dignidad los precede e informa.

\footnotetext{
${ }^{12}$ Héctor C. Silveira Gorski e Iñaki Rivera Beiras - La biopolítica contemporánea ante los flujos migratorios y el universo carcelario. Una reflexión sobre el regreso de los campos en Europa.

${ }^{13}$ Arendt, Hannah - Los orígenes del totalitarismo, Ed.
} 
Creo que la sola consideración de los juicios de Nuremberg, de Ruanda o de la ex Yugoeslavia y su enfrentamiento con los aparentes derechos positivos que justificaran las tecnologías disciplinarias de las bio-políticas desarrolladas en cada uno de esos lugares, resulta demostrativa de un alumbramiento que, como toda invasión, ingresa con paso de paloma.

La aparición de documentos internacionales que sostienen la precedencia de los derechos del ser humano respecto de cualquier ordenamiento jurídico, que han sido reconocidos por las normas fundantes de los Estados y que disciplinan a los gobiernos y al poder, en su conjugación con el sometimiento a Tribunales supranacionales a los que pueden acudir por sí los seres humanos en procura de respaldo de sus dignidades permite atisbar el principio de una realidad cambiante. Ello aparece especialmente calificado cuando se repara en que se impide que los derechos positivos nacionales pudieran deslegitimar o exigir a los reclamantes condiciones especiales para aspirar a ser tratados como ciudadanos y sujetos de derecho en esos foros.

Estamos presenciando una nueva perspectiva en la administración del conflicto poderderecho-ser humano, que ha puesto el acento en este último factor de la relación como determinante de los otros y en la necesidad de no hacer ninguna discriminación en el concepto de humanidad, que no fuera su concreción en la corporeidad ${ }^{14}$.

La idea de la juridicidad como limitante del poder administrativo surge de las enseñanzas de Julio Rodolfo Comadira, quien apuntara la obligación de la Administración de actuar no sólo conforme a la ley en sentido formal (principio de legalidad), sino también al sistema jurídico como unidad (principio de juridicidad), extremo que supone la exigencia de fundar sus conductas en los principios generales del derecho, que derivan de la dignidad de la persona y la naturaleza de las cosas, a la Constitución Nacional y sus principios, a los tratados internacionales, a la ley formal y los reglamentos, a los precedentes administrativos ${ }^{15}$.

Entiendo que la formulación del profesor Comadira es claramente predicable respecto de la sujeción que se impone al gobierno en la formulación y actuación del orden jurídico en la sociedad y que, en ese marco, cualquier autoridad (legislativa, ejecutiva, judicial y hasta constituyente) está hetero-vinculada por unos principios generales del derecho que se asientan en la dignidad del sujeto humano corpóreo. Por ello correspondería asignar a la juridicidad, en este contexto, el calificante: bio-juridicidad.

Es necesario empezar a advertir que sólo el ser humano, en su corporeidad -que es un concepto mucho más amplio y mucho más restringido que la personalidad jurídica-, es poseedor de atribuciones inherentes, que no dependen de ninguna potestad, ni de ningún ordenamiento y que son la causa y finalidad justificante de las potestades y los ordenamientos, generándoles de tal modo una hetero-vinculación originaria.

\footnotetext{
${ }^{14}$ Vuelvo aquí a la obra de Roberto Espósito: "Las personas y las cosas", Ed. Katz, Bs.As. 2016, cuya lectura me parece necesaria.

${ }^{15}$ Comadira, Julio Rodolfo - El principio de juridicidad, discrecionalidad administrativa y situaciones jurídicas subjetivas - incluido en "Curso de Derecho Administrativo" de Julio Rodolfo Comadira, Hector Escola y Julio Pablo Comadira - Ed. Abeledo-Perrot, Bs.As., 2012, Tomo I, pág. 99 y ss., con cita de Alfonso Santiago (Relación entre el derecho natural y el derecho positivo en el sistema jurídico argentino, L.L. 1997, D, pág. 1999); Juan Santamaría Pastor (Fundamentos de Derecho Administrativo, Madrid 1991) y González Navarro, Francisco (Estado social y democrático de derecho).
} 
Y esa hetero-vinculación de las potestades y los ordenamientos por la dignidad del ser humano es, en mi opinión, el signo de los tiempos que nos tocará vivir. Por ello, es hora de sopesar el eventual nacimiento de la bio-juridicidad, una técnica jurídica que tomaría a su cargo -como principio fundante y ordenador- la integralidad del sujeto humano, su corporeidad, su racionalidad y, sobre todo, su dignidad intrínseca, para desde allí “...construir el vivir dignamente y el evitar morir", en tanto principio cardinal, situando aquellos valores como límite al poder y al ordenamiento en tanto garantías esenciales que no cabe sino reconocer inherentes al ser humano.

Las tecnologías de regulación y disciplinarias estarían, en este nuevo campo, dominadas por el principio de la mínima intervención sobre la dignidad del hombre, una intervención sólo justificada por un palmario requerimiento de los derechos a y la procura pública de la dignidad de los demás congéneres, esto es, sólo para superar un conflicto entre dignidades humanas, un concepto más restringido que el que alude a enfrentamiento de derechos.

Y adviértase que esta limitación a la intervención del poder no supone aludir a un retorno al laissez faire, laissez passer, pues está claro que ella está sólo enfocada en la preservación de la dignidad de los seres humanos en cuanto tales, a sabiendas de que la liberación de las fuerzas económicas a sus poderes naturales concluye, por lo general o cuando menos en la experiencia, en el cercenamiento de la dignidad humana.

Tengo bien en claro que la mera postulación de aquellos derechos de la persona humana no será suficiente para enfrentar la bio-política, ni las fuerzas económicas. Sin embargo, no es menos palpable que en una gran parte del mundo la intervención de tribunales supranacionales - la Corte Penal Internacional, el Tribunal de Estrasburgo, la Corte Interamericana y hasta los Tribunales internacionales ad hoc- ha dañado gravemente el autismo de las soberanías y hasta de los poderes económicos a la hora de adoptar o impulsar tecnologías regulatorias o disciplinarias cuyo resultado supone o consiente la desvirtuación de la dignidad de seres humanos, aunque se invoquen de otras ciudadanías o se bauticen como "el enemigo".

Sé que esta postulación pareciera todavía una inocente mirada futura hacia un presente que todavía continúa escrito en términos de bio-política, pero no quiero abandonar la esperanza que supone esta reflexión.

\section{IV.- LAS CATEGORIAS INTERPRETATIVAS DE LA BIOJURIDICIDAD.}

Porque no es menos visible que los tribunales nacionales han empezado a superar las meras sujeciones normativas, para admitir categorías interpretativas que las superan para la protección de principios y bienes que preceden jerárquicamente y trascienden al ordenamiento, como lo demuestra la sentencia de la Corte Constitucional de Colombia en una acción colectiva de protección a los desplazados por la guerra, que declaró la existencia de una situación de hecho inconstitucional ${ }^{16}$.

\footnotetext{
${ }^{16}$ Corte Constitucional de Colombia-Sentencia T-025 de 2004 y los autos de seguimiento de la ejecución.
} 
Como se decía al principio, todo cambio profundo del sistema jurídico requería la constatación de un cambio de la realidad y de las categorías jurídicas interpretativas. Es necesario proponer una nueva mirada sobre el cambio de la realidad social ante el poder y el derecho, pero también hacer un repaso de las categorías con las cuales habremos de interpretar esta realidad que se nos presenta. Y me parece que ello debe hacerse, cuando menos, en tres campos: en el de los derechos humanos y el concepto de humanidad, en el del ordenamiento jurídico y en el de las normas de resolución de conflictos.

\section{(i) Los derechos humanos y la categoría de la humanidad.}

En un trabajo destinado a examinar los criterios de Hanna Arendt, Reyes Mate ${ }^{17}$ recuerda que los derechos humanos son un logro histórico, porque en ellos se mide la dignidad del hombre por el nacimiento y no por la cuna.

Sin embargo, recogiendo lo expuesto por Arendt, Reyes Mate advierte que este hito podría hacerse añicos si resulta que el término hombre es definido por el legislador y por tanto sujeto a la instancia superior de la ley, porque ¿cómo obligarle a respetar toda dignidad si el poder no quiere? ¿A qué instancia acudir si ya no reconocemos la autoridad de Dios, de la polis, de la razón pura y sabemos que el mismo poeder es el autor del ordenamiento?

En este orden si los derechos del hombre se identifican con el ser humano, vacío de todo otro calificativo, no sólo habrá que respetarlos siempre, sino que no podrá ser objeto de exclusiones filosóficas, económicas, religiosas o de otro orden -aunque aceptemos que ellas puedan tener justificados fundamentos para quienes adscriben a esos criterios-. Contrariamente, si supeditamos aquellos derechos a integrar el concepto legal de ciudadano, sólo serán respetados cuando la nación que nos da la ciudadanía, o la creencia religiosa, la razón política o el ideario filosófico, así lo quiera. ¿Qué pasará entonces con los des-naturalizados o desnacionalizados, los refugiados, sin-papeles, retenidos en zonas internacionales de aeropuertos? ¿Estarán los prisioneros de Guantánamo en peor situación que los delincuentes locales, a quienes sí reconocemos el status de personas?

Es posible coincidir con Reyes Mate, en orden a que los Derechos Humanos son la joya de la corona de la modernidad. Sin embargo, darles el valor que esta calificación les otorga, supone repensar su lugar respecto de todos aquellos seres humanos que no tienen más capital que su dignidad de origen, reflexión que se ha vuelto urgente, no sólo por la evolución del hombre y la eliminación de las barreras que supone una aldea global continuamente integrada, sino especialmente por sus consecuencias, concretadas en la importancia de las migraciones en ese mundo globalizado.

Es que ante el fenómeno de un mundo único, no parece posible reinventar discriminaciones que opaquen la dimensión única de la dignidad, bajo supuestas diferencias de cultura, capacidades o discapacidades, evolución social, creencias religiosas, o bajo el manto de la preservación de la estabilidad y estilo de vida de algunos pocos, frente a la hambruna de mucho, pues ello se parecería demasiado a la

\footnotetext{
${ }^{17}$ Reyes Mate - "Hannah Arendt y los derechos humanos", publicado en Arbor, Ciencia, Pensamiento y Cultura - Marzo - Abril 2010 Nros. 241-243.
} 
creación de nuevos campos de concentración para albergar, o más bien para separar de nuestro campo de "conciencia", a los "distintos".

De ello se sigue que la categoría interpretativa de los derechos humanos no puede recalar en la "personalidad", ni mucho menos en la "nacionalidad" o en la ciudadanía, siendo necesario volver al criterio de la corporalidad y la racionalidad como inherentes a la constitución de un "ser humano desnudo" titular de un derecho a la dignidad por su sola condición de tal.

\section{(ii) La categoría del ordenamiento.}

La segunda categoría interpretativa es la de ordenamiento. Signados por las enseñanzas de Villar Palasí, entendemos al ordenamiento jurídico como un conjunto de principios y normas con aptitud para dar respuesta a cualquier conflicto jurídico.

El racionalismo hizo primar la idea de ordenamiento como conjunto de normas que regulan la conducta humana y la vida social, mientras que desde la teoría egológica de Cossio aparece una visión problemática del derecho, poniéndose el foco en la resolución justa de los conflictos ${ }^{18}$.

Pero más allá de una u otra perspectiva, lo cierto es que ha ocurrido un cambio sustancial en el concepto de los ordenamientos a los que veníamos acostumbrados, especialmente en el ámbito del sistema continental de codificación. Porque mientras nuestros ordenamientos se presentan como sistemas cerrados y solo completados por algunos principios, la aparición de Tratados de Derechos Humanos que auto-proclaman su supremacía sobre toda otra norma jurídica nacional, que justamente pretenden vincular, recogen un principio de completa apertura hacia toda interpretación que favorezca la profundización de la dignidad humana a través del llamado "pro homine".

De modo que la categoría del ordenamiento jurídico ha dejado de ser un compartimiento al que acudir para hallar respuestas deductivas, porque necesita ser integrado. Es desde esta perspectiva que, en mi opinión, corresponde atender a lo expuesto por Alfonso Santiago (h), cuando citando a Villey sostiene que el ordenamiento sería una obra colectiva que inicia el constituyente, desarrolla el legislador y finaliza el juez, concretándose así en una concatenación de instancias de producción normativa ${ }^{19}$.

Creo que, a la luz de los criterios que vengo de dibujar en lápiz, deberíamos pensar que ese derrotero no se inicia en la Constitución sino en el ser humano y su dignidad, lugar que debe iluminar el peldaño constitucional y, sucesivamente, a los demás.

\section{(iii) La categoría de la norma de resolución del conflicto.}

Pero todavía es necesario detenerse en la categoría interpretativa de las normas que han de resolver los conflictos.

\footnotetext{
${ }^{18}$ Ver Alfonso Santiago (h) En las fronteras entre el derecho constitucional y la filosofía del derecho Ed. Marcial Pons, Bs.As. 2010, pág. 105 y ss.

${ }^{19}$ Alfonso Santiago (h), op.cit., loc.cit.
} 
En este sentido, ha sostenido John Rawls que "...no importa que las leyes e instituciones estén ordenadas y sean eficientes: si son injustas han de ser reformadas o abolidas. Cada persona posee una inviolabilidad fundada en la justicia que ni siquiera el bienestar de la sociedad en conjunto puede atropellar. Es por esta razón por la que la justicia niega que la pérdida de libertad para algunos se vuelva justa por el hecho de que un mayor bien es compartido por otros. No permite que los sacrificios impuestos a unos sean compensados por la mayor cantidad de ventajas disfrutadas por muchos. Por tanto, en una sociedad justa, las libertades de la igualdad de la ciudadanía se dan por establecidas definitivamente; los derechos asegurados por la justicia no están sujetos a regateos políticos ni al cálculo de intereses sociales. Lo único que nos permite tolerar una teoría errónea es la falta de una mejor; analógicamente una injusticia sólo es tolerable cuando es necesaria para evitar una injusticia aún mayor. Siendo las primeras virtudes de la actividad humana, la verdad y la justicia no pueden estar sujetas a transacciones" 20 .

En términos igualmente útiles para advertir este cambio, afirma Dworkin: "Me propongo llevar un ataque general contra el positivismo...Mi estrategia se organizará en torno del hecho de que cuando los juristas razonan o discuten sobre derechos y obligaciones jurídicas, especialmente en aquellos casos difíciles en que nuestros problemas con tales conceptos parecen agudizarse más, echan mano de estándares que no funcionan como normas, sino que operan de manera diferente, como principios, directrices políticas y otro tipo de pautas ... Llamo 'principio' a un estándar que ha de ser observado, no porque favorezca o asegure una situación económica, política o social se considera deseable, sino porque es una exigencia de la justicia, la equidad o alguna otra dimensión de la moralidad...Los principios tienen una dimensión que falta en las normas: la dimensión de peso o importancia. Cuando los principios se interfieren (la política de protección a los consumidores de automóviles interfiere con los principios de libertad de contratación, por ejemplo), quien debe resolver el conflicto tiene que tener en cuenta el peso relativo de cada uno. En esto no puede haber, por cierto, una mediación exacta, y el juicio respecto de si un principio o directriz en particular, es más importante que otro será con frecuencia motivo de controversia. Sin embargo, es parte esencial del concepto de principio el que tenga esta dimensión, que tenga sentido preguntar qué importancia o qué peso tiene"21.

Advierto, desde ahora, que este modo de concebir la norma de resolución del conflicto no supone una postergación indebida de la legalidad y del interés público, sino la encarnación de estos dos conceptos en un ordenamiento iluminado por la jerarquización máxima del valor: preservación de la dignidad humana, que sólo puede ser postergado ante el agravio a otras dignidades humanas o de las actividades que suponen inmediata $o$ mediatamente su procura. En este campo, pues, el interés público deberá ser reinterpretado desde la dignidad del hombre y no para su postergación por la necesidad fiscal o del orden por el sólo orden.

La admisión de la categoría de la bio-juridicidad supone que la invocación de la emergencia no pueda ser admitida como un telón justificante de toda medida de policía sin que puedan consultarse cuáles han sido las causas que provocaron la emergencia, para evitar que las medidas sólo ataquen a los efectos y mantengan la virtualidad de las razones que le dieron origen. La verdadera emergencia debe ser mirada en términos de

\footnotetext{
${ }^{20}$ John Rawls - Teoría de la justicia - Fondo de Cultura Económica - Mexico 2004.

${ }^{21}$ Ronald Dworkin - Los derechos en serio - Barcelona 2010.
} 
peligro a la dignidad del ser humano y a la realización de sus potencias individuales y sociales.

Es claro que la bio-juridicidad supone la consecución de recursos para la preservación de esa dignidad y realización, como también que muchos poderes económicos no parecieran estar dispuestos a promover inversiones en un contexto con tales presupuestos jurídicos. Será necesario advertirles que existe una nueva seguridad jurídica en la "bio-juridicidad", que podría rendir menos provecho económico inmediato, pero será mucho más duradera en su rentabilidad menor, como también en materia de seguridad personal, de paz social y de convivencia humana. Es preciso advertir que la supuesta seguridad jurídica, construida a base de la subestimación del valor del ser humano, nos ha llevado a un mundo absolutamente frágil, en el que los extremismos de todo signo ponen en vilo la supervivencia de la vida, sin importar cuán altas construyamos las paredes destinadas a rodear nuestra existencia, se hace evidente que la única seguridad consiste en que las personas adviertan en los contextos en los que se hallan o a los que puedan desplazarse un lugar en que les es posible reconquistar su dignidad perdida, construir una vida más posible y que pueda estimarse más que la inmolación, que sólo parte de la subestimación de la propia persona.

\section{V.- LA BIOJURIDICIDAD Y EL DERECHO ADMINISTRATIVO.}

Postular la idea de la "bio-juridicidad" en el campo del derecho administrativo, en el que el poder exhibe todo su poderío y donde los factores económicos pintan cuadros apocalípticos, parecería casi una petición de principio.

Sin embargo, los animo a repensar nuestro objeto de estudio desde esta nueva perspectiva y a comprobar que una leve consulta de la realidad permite comprender que existen claros indicios de esta sustitución de los principios fundantes de la realidad poder-ordenamiento-ser humano, que no dejan de llamar la atención y que señalan no sólo aquel cambio de la realidad, sino también la correlativa modificación de las categorías interpretativas del ordenamiento.

Tomemos sólo unos pocos ejemplos de la realidad argentina, a mi juicio, paradigmáticos:

1) La entronización del derecho a la información pública de las personas físicas gobernadas, por su sola condición de tales y su respaldo por la propia Administración y la Justicia, que conlleva un implícito reconocimiento del poder de contralor general sobre la actividad del poder, como ocurriera con el fallo "Giustiniani",22.

2) El control de la discrecionalidad en la revocación de la designación pendiente la adquisición de la estabilidad en el empleo público (en el caso Micheli ${ }^{23}$ ); la proscripción de la discrecionalidad disciplinaria en este campo (en Spinosa Melo $^{24}$ y en Torres c/Ministerio Público ${ }^{25}$ ) y la reinstauración del equilibrio en

\footnotetext{
${ }^{22}$ Fallos 338:1258.

${ }^{23}$ Fallos 332:2741.

${ }^{24}$ Fallos 329:3617.
} 
la aplicación de la doctrina de los actos propios frente a los contratos de empleo de la Administración (en la causa "Ramos c/Estado Nacional - 'Armada Argentina" ${ }^{, 26}$ y los fallos posteriores de igual signo).

3) La superación de conflictos competenciales para admitir la transversalidad de las obligaciones administrativas cuando se ponen en juego la vida, la salud, la dignidad de las personas o el ambiente (como ocurriera en las causas Mendoza ${ }^{27}$ y "Salas" ${ }^{28}$ y con la adopción de criterios jurisdiccionales de seguimiento de la ejecución ${ }^{29}$ en el Fallo del 4.10.16).

4) La ampliación de los criterios legitimantes en el ámbito del procedimiento administrativo y la inversión de la carga de la prueba en supuesto de obligaciones estatales para restablecer la igualdad ante capacidades diferentes ${ }^{30}$.

5) La subordinación de la interpretación de las relaciones especiales de sujeción a la situación de vulnerabilidad del sujetado (como ocurriera en la causa "Méndez"31, respecto de los condenados en criterio claramente extensible a otras situaciones de vulnerabilidad.

6) La reivindicación del sistema de silencio como derecho y la proscripción de la teoría del silencio ficto, que independientemente de su apego a la literalidad normativa hace pie en la buena fe exigible a la Administración Pública frente a las personas que se relacionan con ella ${ }^{32}$,

7) La jerarquización del procedimiento de audiencias públicas para legitimar decisiones de aumentos de tarifas aún respecto de actividades que se excluyeron conscientemente del concepto de servicio público, como la generación de gas y la postulación de criterios de razonabilidad en el manejo de tarifas respecto de ususarios residenciales (en la causa C.E.P.I.S ${ }^{33}$ ).

8) La sujeción de la validez del procedimiento administrativo y judicial a su resolución en un plazo razonable (Losicer c/BCRA ${ }^{34}$ ) y la admisión de medidas cautelares autónomas o de provisión indemnizatoria, que suponen la transformación de la estructura del contencioso administrativo, de un proceso de pretensiones en un proceso de pretensores, que privilegie al ser humano ${ }^{35}$.

9) La reivindicación del poder del Juez para crear procedimientos cada vez que un derecho personal se encuentre en peligro (que fuera citado en su momento por el

\footnotetext{
${ }^{25}$ Fallos 335:2684.

${ }^{26}$ Fallos 333:311.

${ }^{27}$ Fallos 331:1622.

${ }^{28}$ Fallos 332:663

${ }^{29}$ Ver en la misma causa Salas, Fallos 334:1754, y en la causa Mendoza, fallo del 4 de octubre de 2016.

${ }^{30}$ Fallos 327:2413.

${ }^{31}$ Fallos 334:1216.

${ }^{32}$ Como ocurriera al recoger la Corte Suprema el criterio de la Procuración General de la Nación en la causa "Byosistems".

${ }^{33}$ Fallo de la Corte Suprema del 18.8.2016

${ }^{34}$ Fallos 335:1126.

${ }^{35}$ Fallos 326:4981; 335:452 y las decisiones del Juzgado Federal de San Martín en este sentido.
} 
Juez Marshall y retomado por la Corte Suprema en Siri, Kot y más recientemente en Halabi).

10) La revocación de fallos firmes de la propia Corte Suprema sobre la base de sentencias de la Corte Interamericana, como ocurriera en el caso "Derecho, René" ${ }^{36}$ y el reconocimiento de la obligación de los jueces de hacer un control oficios de constitucionalidad y convencionalidad de modo previo a la aplicación de las normas jurídicas (en el fallo "Rodríguez Pereyra c/Ejército Argentino ${ }^{37}$ ).

Pero es posible predicar este sustancial cambio de perspectiva hacia el derecho en un conjunto de instituciones propias del derecho administrativo, que claman por esa mutación, como en la subordinación de los criterios de habilitación de la instancia a la renunciabilidad de los derechos en juego; el reconocimiento de mayor amplitud a las facultades judiciales en el control de la Administración; la sujeción del procedimiento administrativo a nuevos principios basados en la buena fe y el respeto a los derechos del ciudadano, pero también a la necesidad de dar respuesta a sus requerimientos en un tiempo compatible con las necesidades que se brindan y que no se detienen en la caracterización formal de un reclamo administrativo, un recurso o una denuncia, para justificar la reacción administrativa.

En parecidos términos, podría convocarse una mirada diversa sobre temas tales como los límites de la legitimación en el procedimiento administrativo; los términos en que ha de interpretarse la tutela judicial efectiva a la hora de resguardar los derechos del hombre; la necesidad de hacer regulaciones especiales para algunas especies de contratos administrativos en que tales derechos se encuentran en juego; los límites a la discrecionalidad funcionarial en la definición de perfiles y el procedimiento que gobierna el sistema de acceso y promociones en el empleo público; la importancia de la capacitación como derecho de la persona y obligación de la Administración y de su utilización concreta a la hora de aplicar sanciones correctivas; la regulación efectiva de las audiencias públicas para trascender al mero formalismo; el tratamiento especial que corresponde a las personas discapacitadas y a los niños, en particular en orden a su integración a comunidades que no los expulsen a las tinieblas de la discriminación explícita o implícita; etc.

En todos y cada uno de estos casos era posible postular que la mera legalidad o la aplicación de las tecnologías de la bio-poilítica invitaban a proponer soluciones compatibles con el ejercicio de un poder que establece, por sí, las finalidades predeterminadas por su idea especial de "interés público". Sin embargo, en aquellos casos que se han citado más arriba, los Tribunales prefirieron construir decisiones prudenciales, que en la mayoría de los precedentes tuvieron su acento en la consideración de la dignidad humana y su protección más integral, como elemento integrador del ordenamiento.

Tal vez sea hora de reconocer que el primer principio del derecho, actualmente vigente no es otro que el de respetar la dignidad del ser humano y que todos los demás sólo pueden leerse jurídicamente desde la óptica que brinda su respeto más cabal.

\footnotetext{
${ }^{36}$ Fallos 334:1504.

${ }^{37}$ Fallos 335:2333.
} 
En este contexto, la presentación de la "bio-juridicidad" como traslación de aquello que es inherente a la vida del ser humano corpóreo (esto es: su dignidad más fundamental), al máximo nivel de la pirámide jurídica, de modo que justifique predeterminar desde allí cualquier categoría interpretativa, podrá conducirnos a un derecho más coherente con su finalidad esencial, que no dejará nunca de ser la preservación del ser humano y la realización de sus posibilidades en el ámbito de la vida social.

\section{UNA INVITACION PENDIENTE}

Somos testigos de una época especialmente trascendente de la evolución de la cultura, que se refleja, entre muchos otros campos, en las bases de interpretación de los sistemas jurídicos. Vivimos un tiempo que reivindica el valor de la dignidad del ser humano sin discriminaciones - por ello se alude claramente a su corporeidad-, como centro de la vida social, cultural y económica, convertido así en parámetro para dimensionar la validez del derecho y de las reglas que gobiernan las relaciones intersubjetivas.

Podemos enfrentar este tiempo con la denuncia de la biopolítica y permanecer en la crisis, o contribuir al desarrollo de una mejor respuesta individual y colectiva a las necesidades de la era, que no son sólo de los vulnerables, sino de todas las personas a las que -a veces en otros campos-, incluimos necesaria y moralmente en la categoría de seres humanos.

No tengo la pretensión de establecer una tesis definitoria. Simplemente me propongo alentar a mirar de qué manera ha cambiado la realidad y cómo se han modificado las categorías interpretativas y convocar a una reflexión que nos encamine a una realidad más compatible con la dignidad, que debe ser el norte de todo el sistema jurídico y el límite de todo gobierno. Estará en cada uno de nosotros la instalación de un nuevo criterio de relacionamiento entre el poder, el ordenamiento y el ser humano.

\section{BIBLIOGRAFÍA}

BALBÍN, Curso de Derecho Administrativo, Ed. La Ley, Bs.As. 2007, Tomo I.

COMADIRA, El principio de juridicidad, discrecionalidad administrativa y situaciones jurídicas subjetivas - incluido en "Curso de Derecho Administrativo" de Julio Rodolfo Comadira, Hector Escola y Julio Pablo Comadira - Ed. Abeledo-Perrot, Bs.As., 2012, Tomo I.

DWORKIN, Los derechos en serio, Barcelona 2010

FOUCAULT, El nacimiento de la biopolítica, Ed. Fondo de Cultura Económica, Mexico 2007.

- Genealogía del racismo, Paris 1992. 
MARITAIN, El hombre y el Estado. Capítulo IV, Los derechos del hombre y sus fundamentos, que puede verse también en www.jacquesmaritain.com/pdf/09

RAWLS, Teoría de la justicia, Fondo de Cultura Económica, Mexico 2004.

REYES MATE, "Hannah Arendt y los derechos humanos", publicado en Arbor, Ciencia, Pensamiento y Cultura, Marzo- Abril 2010 Nros. 241-243.

SANTIAGO: En las fronteras entre el derecho constitucional y la filosofía del derecho, Ed. Marcial Pons, Bs.As. 2010.

SILVEIRA GORSKI; RIVERA BEIRAS, La biopolítica contemporánea ante los flujos migratorios y el universo carcelario. Una reflexión sobre el regreso de los campos en Europa.

WILSON, El Estado, con prólogo de León Duguit, Ed. V.Giard \& Briere, París 1902. 